\title{
Remittance and growth nexus: bootstrap panel granger-causality evidence from high remittance receiving countries
}

\begin{abstract}
The present paper examine the causal relationship between economic growth and remittances among the top ten highest remittance recipient countries in the world based on remittance to GDP ratio (Haiti, Honduras, Kyrgyz Republic, Lebanon, Lesotho, Moldova, Nepal, Samoa, Tajikistan, and Tonga). We applied Konya (2006) Bootstrap panel remittance inflows in the case of Lesotho, Nepal, Samoa, and Tajikistan. However, bidirectional causality exists in the case of Haiti whereby remittances cause economic growth and vice versa. Hence, the results reveal that, the causality between the two variables is both one way causality that run from remittances to growth and the other segment that run from economic growth to remittances, therefore the result is mainly country specific.
\end{abstract}

Keyword: Remittances; Economic growth; Granger-causality; Konya; Cross-sectional dependence 